EPiC Series in Language and Linguistics
Volume 2, 2017, Pages 112-118
Professional and Academic Discourse:
an Interdisciplinary Perspective

\title{
Academic Discourse in English Medium Instruction Contexts: A Look at Teacher Explanations
}

\author{
María Ángeles Martín del Pozo \\ Universidad de Valladolid \\ maryange@dlyl.uva.es
}

\begin{abstract}
Teaching and learning content subjects through English requires a competence in academic language which Cummins (1984) labeled CALP (Cognitive Academic Language Proficiency). Revisiting this concept could shed light on the academic language skills necessary for communication in bilingual classrooms. A first step in this long journey could be a deeper comprehension of the academic linguistic or cognitive discourse functions (Dalton-Puffer, 2013). This paper approaches the function of explaining.

To accomplish this aim, six lecturers teaching through English at Escuela de Ingeniería de Informática (Segovia, Spain) were videotaped. Lessons were transcribed to create a corpus. The main research questions followed Dalton-Puffer's (2007) model for a secondary education context:

1. How many occurrences of the academic function of explanation are there in the corpus?

2. What is the linguistic form of these explanations?

3. Is there any signaling language or metalanguage around them?

The seventy explanation fragments found were classified in three categories following Brown's taxonomy (2006).

- Interpretative explanations respond to the question 'What?' and are very close to definitions.

- Descriptive explanations respond to the question 'How?' and centre on processes, structures and procedure.

- Reason giving_explanations respond to the question 'Why?' and provide reasons and causes.

The findings show a rich frequency of this academic function in contrast to the very limited comparable previous studies in bilingual classrooms (Dalton-Puffer, 2007). Bar graphs of frequencies and distribution of types per lecturer are presented. Regarding qualitative aspects, the samples found offer insights about how explaining is performed
\end{abstract}


in bilingual content lectures. The form of these explanations and the metalanguage signaling them are analyzed and illustrated with numerous examples from the corpus.

Taking as starting point the description of the explanations present in lecturer discourse some reflections about their potential for the learning of content and language are provided. The conclusions section suggests some pedagogical implications for the linguistic education of both students and lecturers in English medium instruction environments.

\section{Introduction}

CLIL (Content and Language Integrated Learning) and EMI (English Medium Instruction) are perhaps the most popular versions of bilingual education in Spain. CLIL has a dual objective of language and content and this term is preferred for Primary and Secondary Education. On the contrary, EMI is content driven and its scope reaches higher education only. These two different practices require very different approaches. The research reported here refers to a higher education, however implications and factors could also be transferable to CLIL contexts.

Teacher training is one of the main concerns for theorists and practitioners and also considered a key factor for CLIL / EMI implementation and success (Coyle, Hood \& Marsh, 2010).

Competences lists and teacher training frameworks identify two main domains for teacher education, the linguistic domain and the methodological domain (Lasagabaster \& Ruiz de Zarobe, 2010; Doiz, Lasagabaster \& Sierra, 2012; Ball, \& Lindsay, 2012; Martín del Pozo 2013, inter alia.) Both still require further specification. This paper aims to contribute to the specification of the linguistic competences of CLIL / EMI teachers. The research to date has tended to focus on the product on CLIL/EMI instruction (language learning gains) rather than on the process of teaching and learning. Considering the elements in this process could provide valuable insights of linguistic and didactic variables which could be targeted by teacher trainers. The small scale investigation carried out seeks to describe the academic language used in bilingual contexts in order to identify teachers' linguistic needs. Figure 1 illustrates the position taken by this paper among the different perspectives on CLIL research.

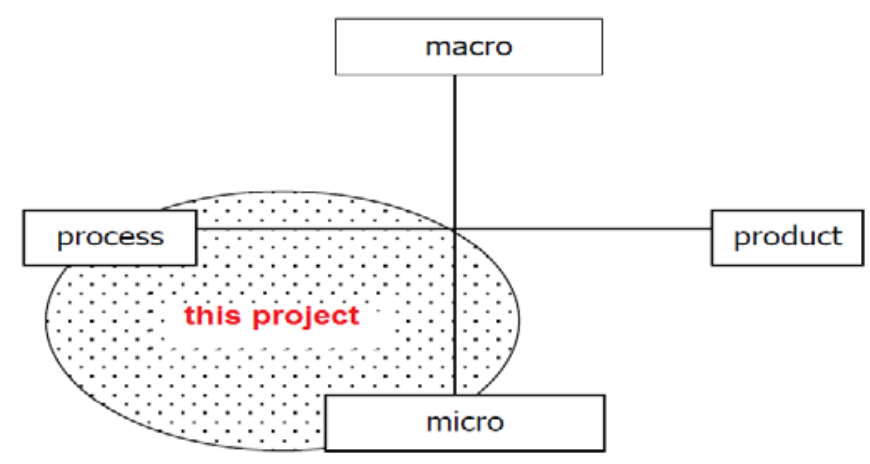

Figure 1. Perspectives for CLIL research. Dalton-Puffer and Smit (2008:14) 


\section{Academic Functions: Presence and Relevance in CLIL /EMI}

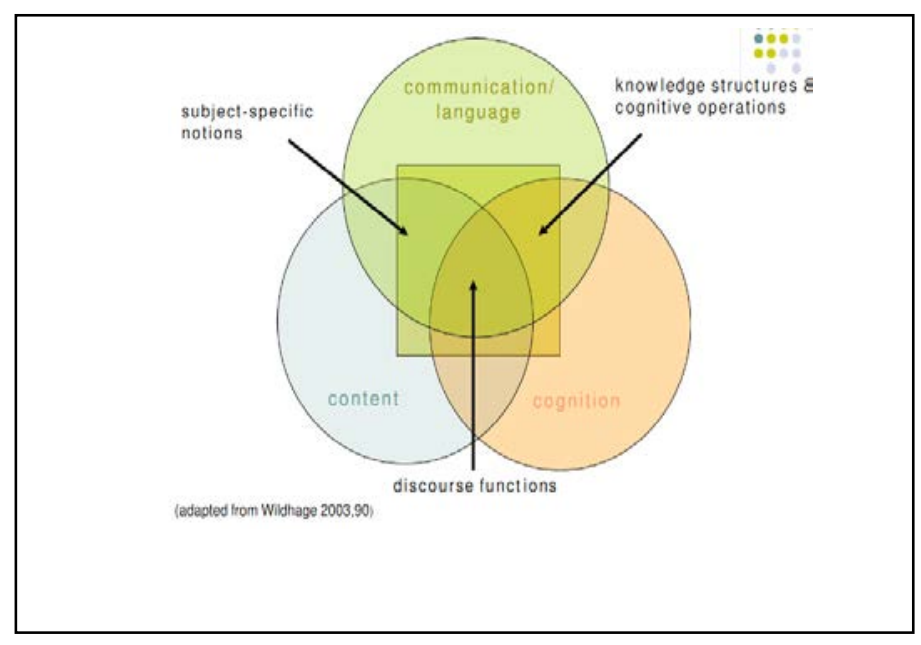

Figure 2. Academic discourse functions.

Dalton- Puffer (2012)

Academic functions:

- Describing

- Narrating and reporting

- Defining

- Explaining

- Contrasting

- Expressing hypothesis

- Arguing

\section{Context}

The data for this study were collected at Escuela Universitaria de Informática (Universidad de Valladolid, Campus Segovia). Teaching through English was an optional practice from 2006 to 2013. This is an EMI context which lacks explicit language objectives neither at institutional nor at individual level. Nonetheless, it is expected that students' linguistic competence will benefit from the bilingual program Ingeniero técnico de informática de gestión. There were twelve lecturers involved, all content experts, and more than 50 students. The subjects taught through English at Escuela de Informática ranged from Economics, Operating systems, software engineering, Math, Physics, Information Systems, Programming and other related knowledge areas. The number of credits in English increased from 26 to 117 during this period. During the first two years of the program, the author of this paper provided some training to the lecturers involved, mainly conversation and academic English lessons. The data presented here are part of an in depth multiple case study that includes detailed transcription and analysis of classroom discourse and which served the researcher as Doctoral thesis.

Six lectures from different subjects were videotaped and the verbal language was transcribed. The corpus had 16, 413 words. 


\section{Research Questions and Methodology}

As already said in the theoretical framework, academic linguistic function have a prominent role in academic discourse and are a key factor in cognition. This paper focuses on a better understanding of the academic function of explanation. More specifically, the research questions to be answered are:

1. How frequent are explanations in the data?

2. What linguistic form do explanations present?

3. Is there any signalling language or metalanguage around them?

The methodology used draws on case study, qualitative methodology and the specific areas of research in Language Didactics. As a case study, it is expected that knowledge of the particular (features of the discourse of six lecturers teaching through English in this specific context) will provide knowledge about the general (features of any lecturer teaching a non linguistic discipline through English). Data are qualitative; therefore categories need to be identified. The linguistic analysis of these date required the design of taxonomies based on previous models.

Thus, the first step was to identify explanations in lecturer's discourses. Explanations are difficult to identify because they lack the structural and functional regularity of other academic functions such as definition. On the other hand explanations are pervasive rather than identifiable at particular points in the interaction' (Dalton-Puffer, 2007: 152).

A second step in the methodology was to classify the explanation. For that, a taxonomy used for dyadic situations (in education, health science) was found to be suitable. Brown $(1986,2006)$ identifies three types of explanations:

1. Interpretative explanations respond to the question 'What?' and are very close to definitions.

2. Descriptive explanations respond to the question 'How?' and centre on processes, structures and procedure.

3. Reason giving explanations respond to the question 'Why?' and provide reasons and causes.

\section{Findings}

Figure 3 displays the frequency and types of explanation per lecturer. However, the most useful analysis is not the quantitative but the qualitative. The linguistic form of the explanation provides the most valuable information for the purpose of the research.

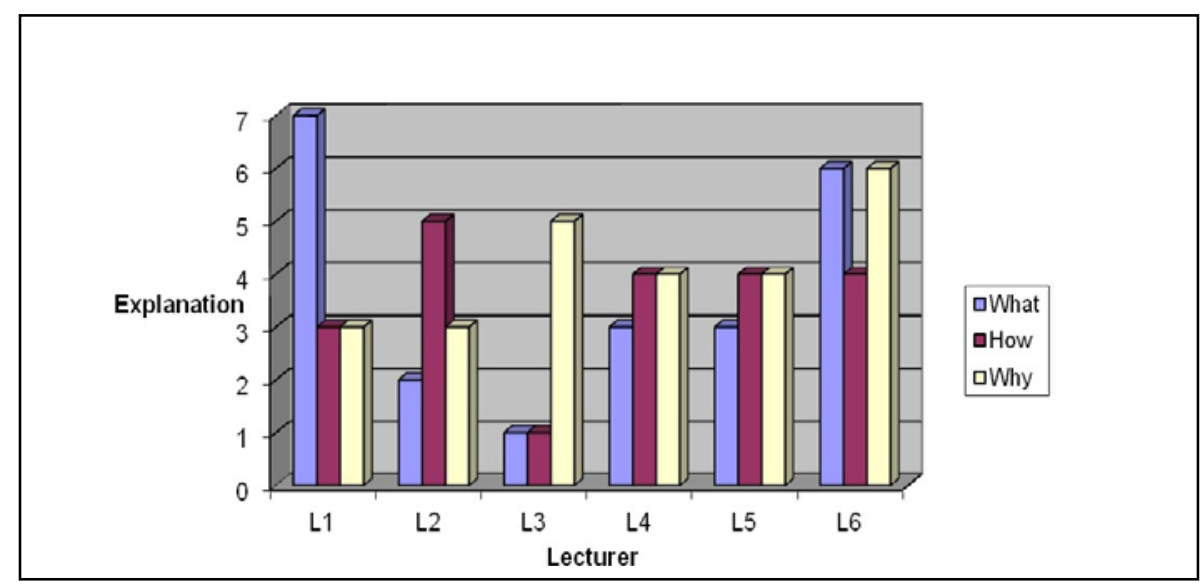

Figure 3 displays the frequency and types of explanation per lecturer 
The data provide important insights into the features of Spanish lecturers explaining in English to teach content subjects. Regarding the first research question, the frequency of explanations in the corpus, the discourse of the investigated lecturers shows a more favorable number of occurrences than Dalton-Puffer's (2007) data. This finding supports the recommendation of 'reconsidering the value of teacher monologue (in well-considered dosage), both in the interest of presenting coherent conceptual networks of topic content and in the interest of providing sustained, syntactically complex oral input' (Dalton-Puffer, 2007: 296).

The distribution of this function and the different subcategories (Figure 3) suggest that the frequency and the type of explanations could be very much dependent on discipline or/and topic of the lectures. For example, the topic chosen by lecturer 4, consumer behavior, demanded reason giving explanations. On the contrary, the Operating Systems lecture (L1) focused on interpretative explanations. Both Mathematics lecturers (4 and 5) present a very similar frequency of the three types of explanations.

This quantitative information is interesting. However, the most important and relevant information comes from the qualitative analysis of the data. For this, some literal extracts from the corpus are commented, mainly to answer research question two: What linguistic form do explanations present?

One of the most relevant linguistic features of explanations found in our data is the use of inclusive personal pronouns (we, our) or pronouns to address the receptor (you, your). This is found in explanations how which refer mainly to processes and procedures. In sample 1, 2, and subsequent one $\mathrm{L}$ stands for Lecturer and $\mathrm{m}$ stand for minute.

1. Euler's theorem [...] there is a method that consists of the following. Initially we take a point, a vertex, V1 and then you have $\mathrm{G}$ and you have to construct $\mathrm{C}$ as ??? a how to try $\mathrm{C}$ you start with a point and then you consider. You start from $\mathrm{H}$ and then while $\mathrm{H}$ has edges you have to find a cycle in $\mathrm{H}$ incident in a vertex of C (L4 m44)

2. To multiply, to, to multiply two powers with the same base, you keep the base and you just add the exponents. To divide them you keep the base and you subtract the exponents and this way (L5 m4)

There are only two occurrences of passive structures in the corpus. The impersonal forms are in detriment regarding personal ones as the use of you illustrates in samples 1 and 2 or the use of we in samples 5 and 6.

The presence of elements to establish an order such as sequencers and elements referring to the different parts of a process is a second frequent feature of explanations. In sample 1 we find the sequencers then, initially and verbs like start. Lecturers enrich the process explanation with sequencers and verbs indicating sequence such as start, continue terminate, and end.

The repetitive use of because as the main conjunction to express causal relationships allowed an easy identification of Explanations why, samples 3 and 4. A repetitive minimal use of formal complexity or variety is a third feature of the linguistic form of this academic function in our corpus.

3. Not possible, because If I take 4 I must give you 4 . If I take 2 is impossible that I must give you 10 (L3 m17)

4. Because these numbers are very easy to see, because you just focus on a particular vertex. You can sum all edges, $8+10+18$ and then the sum of the degrees is the double of the number of vertices, there should be 18 vertices ( $\mathrm{L} 4 \mathrm{~m} 22$ )

Regarding research question three, only two samples of metalanguage were found. These are the performative lexemes such as explanation and explain.

5. We are now trying to explain the central part of of the subject, of this Euler Circuits. So let's start with some history. Graph theory began in history when Euler was asked to solve the so called Konigsberg Seven Bridge Problem (L4 m24)

6. And as you have heard we have mentioned another concept we need to explain first. (L6 m2) 


\section{Conclusions}

The research findings summarized in this paper suggest that the debate about teacher education for CLIL /EMI would be more productive if attention focused on the type of language required for successful CLIL rather than concentrating on language qualifications. It is evident that those who are to teach in English need language upskilling in academic language. This paper has approached one aspect of this academic language, the academic function of explanation.

The results provide important insights into the features of Spanish lecturers using English to teach content subjects. These results complement previous studies such as Dafouz (2011). Some main linguistic needs EMI lecturers can be inferred from these results. Thus, the pedagogical implications derived from the findings could be grouped into two categories:

1. Linguistic needs regarding the particular investigated element, that is the academic function of explanation,

2. A more general category which comprehends linguistic needs derived from global features of lecturer discourse.

Regarding the first one and more specifically, Explanations in the corpus point towards the convenience of including impersonal forms to achieve formal register. The repetitive and exclusive use of because in giving reasons for explanations in the data suggest another need: to enhance stylistic variety to express causality. The same applies to conjunctions in process explanations. In this case, then and the signaling noun way were the most repeated options.

The required training derived from the analysis can be summarized as follows:

1. Awareness of the types of explanations, of their importance and of the assistance that metalanguage could provide.

2. Linguist tools formulate explanations: sequencers, impersonal forms...

3. Stylistic variety and more complex structures when explaining.

Finally, the conclusions of this research endorse the convenience of a more direct focus on academic language form, of the need of explicit linguistic objectives to trigger Cognitive Academic Language Proficiency (CALP) development and of raising lecturers' awareness about how academic language is used in the different disciplines for content transmission and to assist students in knowledge construction.

\section{References}

Ball, P. \& Lindsay, D. (2012). Language demands and support for English Medium Instruction in tertiary education. In. A. Doiz, D. Lasagabaster, \& J.M. Sierra (eds.) English-Medium Instruction at Universities: Global Challenges., (pp. 44-64). Bristol: Multilingual Matters.

Brown, G. (2006). Explaining. In O. Hargie (Ed.). The Handbook of Communication Skills. (pp.204- 224) London: Routledge. $1^{\circ}$ ed 1986.

Coyle, D., Hood, P., Marsh, D. (2010) Content and Language Integrated Learning Cambridge: Cambridge University Press

Brown, G. (2006). Explaining. In O. Hargie (Ed.). The Handbook of Communication Skills. (pp.204- 224) London: Routledge. $1^{\circ}$ ed 1986.

Brown, G. \& Atkins, M. (1998). Effective Teaching in Higher education. London: Routlege

Cummins, J. (1984). Bilingualism and special education: Issues in assessment and pedagogy. Clevedon, England: Multilingual Matters.

Dafouz Milne, E. (2007) On Content and Language Integrated Learning in Higher Education: the case of University Lectures. RESLA, Revista Española de Lingüística Aplicada, Vol, 1. 67-82. 
Dafouz Milne, E. (2011) English as the medium of instruction in Spanish contexts: A look at teacher discourse, en Ruiz de Zarobe, Y., Sierra, J.M. y Gallardo del Puerto, F. (eds) Content and Foreign Language Integrated

Dafouz, E. \& Núñez B. (2010). Metadiscursive devices in university lectures: A constrastive analysis of L1 and L2 performance. Language use and language learning in CLIL classrooms. Eds. Christiane Dalton-Puffer, Tarja Nikula, \& Ute Smit. Amsterdam; Philadelphia: John Benjamins. 213231.

Dalton-Puffer, C. (2007). Discourse in Content and Language Integrated Learning (CLIL). Amsterdam: John Benjamins Publishing

Doiz, A., Lasagabaster, D. \& Sierra, J. M. Eds. (2012). English-Medium Instruction at Universities: Global Challenges. Bristol: Multilingual Matters.

Martín del Pozo, M. A. (2013). Formación lingüística del profesorado universitario para la docencia en inglés. Revista de Docencia Universitaria. REDU, 11 (3). 197-218.

Martín del Pozo, M.A. 2014. Aproximación lingüístico didáctica al discurso académico de la clase magistral en la formación del profesorado en contextos universitarios bilingües. Tesis doctoral. Universidad Complutense de Madrid. 